D. P. Ornatsky, DSc

\title{
ANALOG INTERFACE FOR CAPACITY MOTION SENSOR OPEN FIELD
}

An analytical review of existing methods for measuring small capacitances is performed. Analogue interface for remote measurements of initial parameters capacitance displacement sensors with an open field with improved metrological characteristics is designed.

Keywords: capacitive displacement sensor with an open field, the parasitic capacitance connection cables, error.

УДК 681.5.08

\section{В. П. Квасніков, д.т.Н., А. О. Возняковський}

Начіональний авіаційний університет, м. Київ

\section{МЕТОДИКА БАЛАНСУВАННЯ ЧУТЛИВОГО ЕЛЕМЕНТУ МАЯТНИКОВОГО АКСЕЛЕРОМЕТРА}

Маятникові акселерометри широко застосовуються в космічних апаратах, авіаиії, автомобілебудуванні, ракетах та кораблях. Один з найважливіших елементів конструкиї маятникових акселерометрів - підвіси, їх форма і розміри визначають важливий параметр приладів - чутливість. На чутливість підвісу впливає маятниковість та співпадання иентру мас з віссю горизонту або вертикалі. В статті йде мова про методику балансування чутливого елемента.

Ключові слова: акселерометр маятниковий, чутливий елемент, балансування.

\section{Ветуп}

Проблема точності маятникових акселерометрів для сучасних апаратів $\epsilon$ одною із ключових при розробці високоточних пристроїв. Метод балансування за допомогою лазерного випарювання металу дозволяє випарювати 3 поверхні чутливого елемента надмалі маси, що дозволяє 3 високою точність відбалансувати підвіс.

\section{Аналіз останніх досягнень}

B poботах $[1,2]$ наведена математична модель чутливого елемента на пружному підвісі. Виконано дослідження двох основних форм коливань.

В роботі [3] досліджено вплив деяких технологічних факторів на внутрішне тертя при балансуванні. Отримані результати можуть бути використані на етапі проектування датчиків.

Розробка програм чисельного інтегрування рівнянь руху виконана автором у статті [4]. Отримані автором статті [4] результати зіставлялися 3 експериментальними даними i показали цілком задовільну збіжність.

Завданням, що ставилося при написанні статті, було розробка методики для обрахунку маси, необхідної для випаровування із поверхні чутливого елементу за допомогою лазерного променя, для отримання можливості виставки чутливого елемента в вісь горизонту чи вертикалі. Дана методика дозволяє зменшити похибку вимірювання прискорення.

\section{Виклад основного матеріалу}

Для отримання необхідних співвідношень, що визначають додаткову масу, на величину якої необхідно змінити в процесі юстування основний балансувальний вантаж, розглянемо акселерометр у двох положеннях чутливого елемента по відношенню до вертикалі місця - в положенні нижнього маятника i в положенні верхнього маятника.

При суміщенні базової площини приладу 3 площиною горизонту маятник займе положення як це показано на рис. 1.

Чутливий елемент в положенні нижній маятник

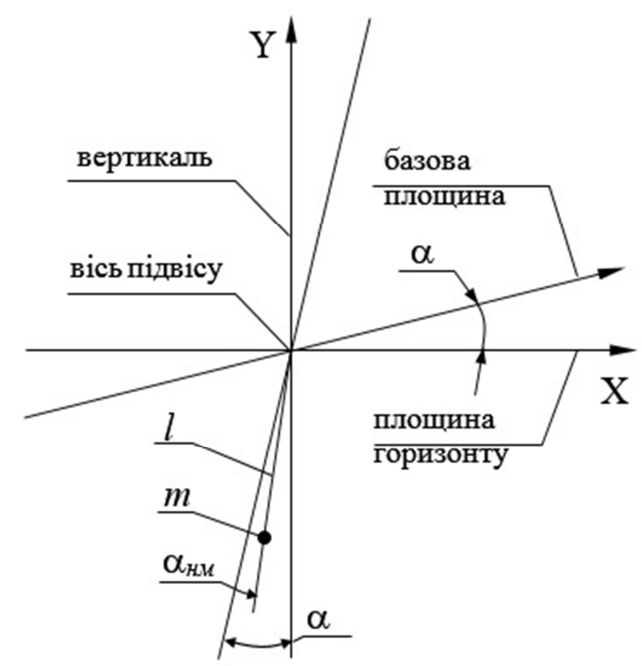

Рисунок 1 - Положення нижній маятник 
Якщо у вихідному положенні момент, створюваний пружними перемичками $M_{y}=0$, то після повороту для положення рівноваги можна записати:

$$
M_{M}-M_{y}=0,
$$

де $M_{м}=M_{0} \cdot g\left(\alpha-\alpha_{н м}\right)$ (у припущенні, що кути $\alpha$ і $\alpha_{\text {нм }}$ - малі); $M_{0}=m \cdot l-$ маятниковість $\left(M_{\text {розрах }}=5,14 \cdot 10^{-6}\right.$ кг $\left.\cdot \mathrm{M}\right) ; \alpha-$ конструктивний кут, що визначає похибку акселерометра; $\alpha_{\text {нм }}$ кут закрутки пружних перемичок, $g=9,81 \mathrm{~m} / \mathrm{c}^{2}$; $M_{y}=K_{y} \alpha_{u \mu}, K_{y} \quad-\quad$ жорсткість підвісу ( $K_{\text {y розрах }}=4,133 \cdot 10^{-4}$ Нм/рад).

Із (1) для вихідного положення (до юстування) знаходимо:

$$
\alpha_{0}=\frac{K_{y}+m l \cdot g}{m l \cdot g} \cdot \alpha_{0, \mu n}=(\varepsilon+1) \cdot \alpha_{0, н u},
$$

де $\varepsilon=\frac{K_{y} \cdot \alpha}{m l \cdot g \cdot \sin \alpha}$.

Для малих кутів $\alpha: \varepsilon=\frac{K_{y}}{m l \cdot g}$.

Звідси для розрахункових значень $K_{y}$ i $m l$ отримуєм $\varepsilon=8,2$.

Для забезпечення $\alpha=0$, в рівнянні (2) необхідно додати додатковий момент $\Delta M$, підбором якого можна забезпечити виконання цієї умови:

$$
M_{м}-M_{y}-\Delta M_{н м}=0 .
$$

Вирішивши це рівняння відносно $\alpha$, із врахуванням (3) отримуємо:

$$
\begin{gathered}
\alpha=\frac{K_{y}+m l \cdot g}{m l \cdot g} \cdot \alpha_{0, н и}-\frac{\Delta M_{\text {ни }}}{m l \cdot g}= \\
=\alpha_{0}-\frac{\Delta M_{u м}}{m l \cdot g} .
\end{gathered}
$$

Підставивши $\alpha=0$, отримаємо вираз для визначення $\Delta M_{н м}$ :

$$
\begin{gathered}
\Delta M_{н м}=\left(K_{y}+m l \cdot g\right) \cdot \alpha_{0, н м} \text { або } \\
\Delta M_{н м}=m l \cdot g \cdot(1+\varepsilon) \cdot \alpha_{0, н м} .
\end{gathered}
$$

Для того щоб після юстування $\alpha=0$, необхідно:

$$
\begin{aligned}
\Delta M_{н м} & =m l \cdot g \cdot \alpha_{0} \text { або } \\
\Delta M_{н и} & =m l \cdot g \cdot(\varepsilon+1) \cdot \alpha_{0, н и} .
\end{aligned}
$$

Після суміщення базової площини 3 площиною горизонту, отримаємо:

$$
M_{M}-M_{y}=0,
$$

де $M_{M}=M_{0} \cdot g\left(\alpha+\alpha_{g m}\right), \quad M_{y}=K_{y} \alpha_{6 m}$, $\alpha_{6, M}-$ кут закрутки пружних.

При суміщенні базової площини приладу 3 площиною вертикалі маятник займе положення як це показано на рис. 2.

Чутливий елемент в положенні верхній маятник

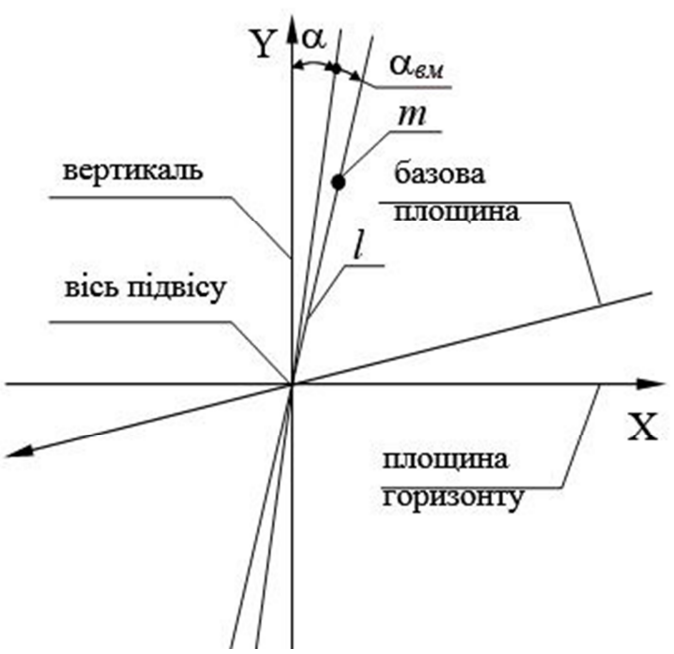

Рисунок 2 - Положення верхній маятник

Із (1) для вихідного положення (до юстування) знаходимо:

$$
\alpha_{0}=\frac{K_{y}-m l \cdot g}{m l \cdot g} \cdot \alpha_{0,6 M}=(\varepsilon-1) \cdot \alpha_{0,6 n} .
$$

Додамо додатковий момент $\Delta M_{6 m}$ в (8) i запишемо вираз для $\alpha$ :

$$
\alpha=\frac{K_{y}-m l \cdot g}{m l \cdot g} \cdot \alpha_{0, s u}-\frac{\Delta M_{s u}}{m l \cdot g}=\alpha_{0}-\frac{\Delta M_{s u}}{m l \cdot g} .
$$

Iз рівняння (9), підставивши $\alpha=0$, знайдемо $\Delta M_{6 м}$ :

$$
\begin{gathered}
\Delta M_{в и}=\left(K_{y}-m l \cdot g\right) \cdot \alpha_{0, в и} \\
\text { або } \Delta U_{\text {вн }}=m_{6 g}(1+\varepsilon) \alpha_{0, н и}
\end{gathered}
$$


Покажемо, що $\Delta M_{u м}$ і $\Delta M_{\varepsilon n}$, розраховані за формулами (5) і (6), відповідно, тотожно рівні. 3 цією метою знайдемо зв'язок $\alpha_{u и}$ i $\alpha_{\epsilon и}$.

Розділимо (9) на (10) і після нескладних операцій, отримаємо:

$$
\alpha_{0, B M}=\frac{K_{y}+m l \cdot g}{K_{y}-m l \cdot g} \cdot \alpha_{0, н и}=\frac{\varepsilon+1}{\varepsilon-1} \cdot \alpha_{0, н M} .
$$

Це співвідношення залишається справедливим для малих $\alpha_{0}$.

Підставимо (11) в (10), отримаємо:

$$
\Delta M_{\text {вм }} \equiv\left(K_{y}+m l \cdot g\right) \cdot \alpha_{0, н м} \equiv \Delta M_{н м},
$$

що і потрібно було показати.

Підставивши в (12) розрахункові значення $K_{y}$ і $m l \cdot g$, отримаємо:

$$
\alpha_{0, в м} \cong 1,28 \cdot \alpha_{0, \text { нм}} .
$$

Для визначення $\Delta M$ підставимо в (13) значення $\mathrm{ml} \cdot \mathrm{g}$ і $\varepsilon$, отримаємо:

$$
\begin{aligned}
& \Delta M=5,01 \cdot 10^{-5} \cdot(1+8,2) \cdot \alpha_{0, \mu u}= \\
& =4,61 \cdot 10^{-4} \alpha_{0, н u} .
\end{aligned}
$$

Помножимо і поділимо праву частину (12) i (14) на крутизну вихідної характеристики датчика моменту $-K_{\partial y}$, отримаємо значення $\Delta M$, виражене через вихідний сигнал датчика моменту виміряний, або при нижній $\left(U_{\mu м}\right)$, або при верхній $\left(U_{\text {ви }}\right)$ маятниковості:

$$
\left.\begin{array}{c}
\Delta M=\frac{m l \cdot g(\varepsilon+1)}{K_{\partial y}} \cdot U_{u м} \\
\Delta M=\frac{m l \cdot g(\varepsilon-1)}{K_{\partial y}} \cdot U_{\varepsilon u}
\end{array}\right\},
$$

де $U_{\text {нм }}=K_{\partial у} \alpha_{0, н и}, U_{в м}=K_{\partial y} \alpha_{0, в м}$.

Формули справедливі, коли постійне зміщення нульового сигналу ДК $U_{0}=0$. Тому до визначення $U_{\text {нм }}$ i $U_{\text {вм }}$ необхідно провести виставку ДК з метою забезпечення $U_{0}=0 \pm \Delta U_{0}$ , де $\Delta U_{0}-$ допустиме значення похибки виставки.

Щоб виставити $U_{0}$ необхідно встановити ЧЕ так, щоб вісь його підвісу була близька до вертикалі місця. У цьому положенні сигнал ДК можна представити у вигляді суми двох складових:

$$
U_{\partial y, 0^{\circ}}=U_{0}+\Delta U,
$$

де $\Delta U$ - складова сигналу ДК визначається неспівпадінням осі підвісу ЧЕ з вертикаллю при установці його на оптичній ділильній головці; індекс $0^{\circ}$ відповідає вихідному положенню шпинделя оптичної ділильної головки.

При розвороті шпинделя оптичної ділильної головки від вихідного положення на кут $180^{\circ}$ значення вихідного сигналу буде визначатися виразом:

$$
U_{\partial y, 180^{\circ}}=U_{0}-\Delta U,
$$

3 рис. 3 а, б видно, що в положенні $0^{\circ}$ i $180^{\circ}$ $\Delta \mathrm{U}$ дійсно повинні бути однакові по модулю і спрямовані в протилежні сторони.

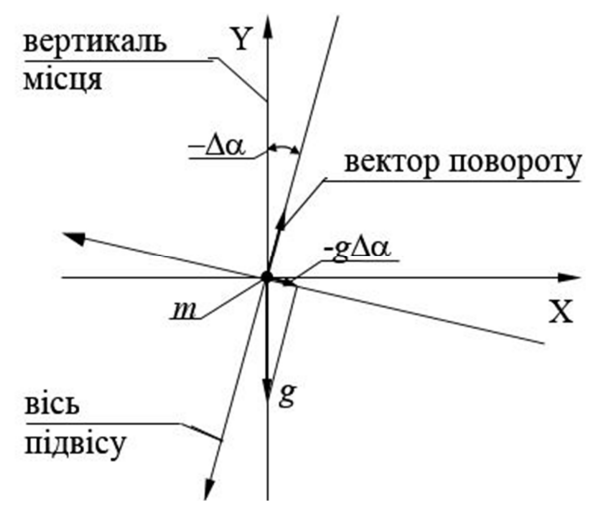

a)

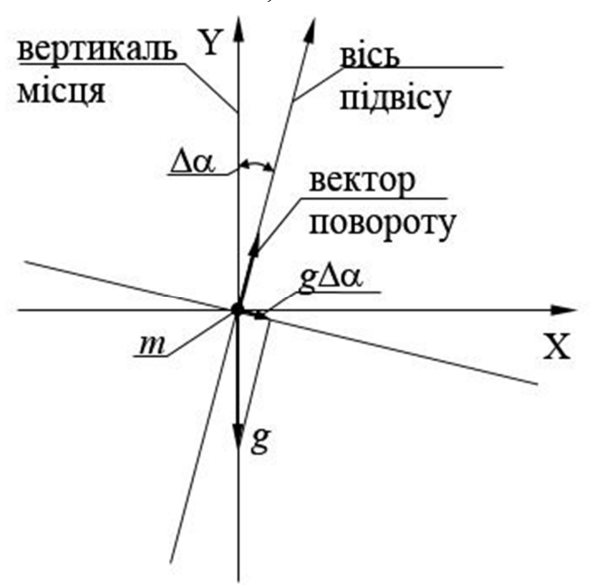

б)

Рисунок 3 - Положення вектору:

a) $0^{\circ}\left(\Delta U=K_{\partial y} \Delta \alpha\right)$; б) $180^{\circ}\left(\Delta U=-K_{\partial y} \Delta \alpha\right)$

На основі (16) і (17) можливо записати:

$$
U_{0}=\frac{U_{\partial y, 0^{\circ}}+U_{\partial y, 180^{\circ}}}{2} .
$$


Використовуючи формулу (18), визначимо додаткову масу, на яку потрібно збільшити або зменшити величину балансувального вантажу. Якщо позначити $r$ радіус, на якому відбувається зміна маси, замість (18) можливо записати:

$$
\left.\begin{array}{c}
\Delta m=\frac{m l(\varepsilon+1)}{r \cdot K_{\partial y}} \cdot U_{\mu u} \\
\Delta m=\frac{m l(\varepsilon-1)}{r \cdot K_{\partial y}} \cdot U_{в м}
\end{array}\right\},
$$

де $\Delta m$ - зазначена додаткова маса.

Враховуючи розкид вимірів при визначенні $\Delta m$ для випадків нижнього i верхнього положення маятника, слід усереднити результати розрахунків за формулами (19). На підставі (19) можна записати формулу для обчислення $\Delta m_{c p}$ :

$$
\Delta m_{c p}=\frac{m l}{r \cdot K_{\partial y}}\left[\varepsilon\left(\frac{U_{u n}+U_{s u}}{2}\right)+\frac{U_{u n}-U_{s u}}{2}\right] .
$$

Виключимо 3 формул для розрахунку $\Delta m$ величину $\varepsilon$, що залежить від жорсткості підвісу $K_{y}$, експериментальне визначення якого вимагає розробки спеціальної методики.

Помноживши праву та ліву частини (19) на $K_{\partial y}$ отримаємо:

$$
U_{6 H}=\frac{\varepsilon+1}{\varepsilon-1} U_{\mu M}
$$

Якщо ввести позначення $v=\frac{U_{6,}}{U_{\mu м}}$, то можна отримати наступне співвідношення, що зв'язує $\varepsilon$ i $v$ :

$$
\varepsilon=\frac{v+1}{v-1}
$$

Підставимо (22) в (19) отримаємо формулу для визначення додаткової маси балансувального вантажу

$$
\left.\begin{array}{c}
\Delta m=\frac{2 m l}{r \cdot K_{\partial y}} \cdot \frac{v}{v-1} U_{u м} \\
\Delta m=\frac{2 m l}{r \cdot K_{\partial y}} \cdot \frac{1}{v-1} U_{в м}
\end{array}\right\},
$$

Для практичного здійснення розглянутого методу балансування чутливого елементу передбачається використовувати методику лазерного випаровування матеріалу з поверхні балансувального вантажу. Такий спосіб видалення матеріалу для деталей зі сталі на заводі добре відпрацьований. Для деталей із бронзи лазерне випаровування металу відбувається інакше, ніж у деталей із сталі.

\section{Висновки}

В даній роботі було розглянуто метод балансування чутливого елемента маятникового акселерометру в горизонтальній та вертикальній осі положення чутливого елементу.

Запропоновано метод та аналітичний розрахунок величини маси необхідної для видалення 3 поверхні задля балансування чутливого елементу.

Запропонована методика може використовуватись при проектуванні нових маятникових компенсаційних акселерометрів для подальшого застосування в інерціальних системах.

\section{Список використаних джерел}

1. Распопов В. Я. Датчики уровня систем управления железнодорожных машин / В. Я. Распопов, Ю. В. Иванов. - Тула: ТулГУ, 2000. $-174 \mathrm{c}$.

2. Распопов В. Я. Математическое моделирование акселерометра прямого измерения с монокристаллическим маятником / В. Я. Распопов // Датчики и системы. - 2000. №3. - С. $22-26$.

3. Обухов В. И. Технология интегральных измерительных преобразователей В. И. Обухов. - Нижний Новгород: РИО НГТУ, 1996. $-150 \mathrm{c}$.

4. Возняковський А.О. Визначення жорскісних параметрів пружинних амортизаторів / А. О. Возняковський, В. П. Квасніков // Технологічний аудит та резерви виробництва. - 2016. - №3/2 (29). - С. 8 $-12$.

\section{Надійшла до редакиї̈ 20.05.2016}

Рецензент: д.т.н., проф. Братченко Г.Д., Одеська державна академія технічного регулювання та якості, м. Одеса. 


\section{В. П. Квасников, Д.Т.Н., А. О. Возняковский}

\section{МЕТОДИКА БАЛАНСИРОВКИ ЧУВСТВИТЕЛЬНОГО ЭЛЕМЕНТА МАЯТНИКОВОГО АКСЕЛЕРОМЕТРА}

Маятниковые акселерометры широко применяются в космических аппаратах, авиачии, автомобилестроении, ракетах и кораблях. Один из важнейших элементов конструкции маятниковых акселерометров - подвесы, их форма и размеры определяют важный параметр приборов - чувствительность. На чувствительность подвеса влияют маятниковость и совпадение центра масс с осью горизонта или вертикали. В статье идет речь о методике балансировки чувствительного элемента.

Ключевые слова: маятниковый акселерометр, чувствительный элемент, балансировка.

\section{Kvasnikov, PhD, A. Vozniakovskyi}

\section{THE TECHNIQUE OF BALANCING THE SENSITIVE ELEMENT OF THE PENDULUM ACCELEROMETER}

Pendulum accelerometers are widely used in spacecraft, aircraft, automotive, missiles and ships. One of the most important elements of the design pendulum accelerometers - suspension, their shape and dimensions determine an important parameter of the instrument - sensitivity. On sensitivity affects pendular and coincidence the center of mass with horizontal or vertical axis. The article deals with the method of balancing the sensor element.

Keywords: pendulum accelerometer, the sensing element, balancing.

\section{УДК 519.878 .5}

В.Ф. Оробей ${ }^{1}$, д.т.н., А.Ф. Дащенко ${ }^{1}$, д.т.н., Л. В. Коломиец ${ }^{2}$, д.т.н., А. Н. Лимаренко ${ }^{1}$, к.т.н.

${ }^{1}$ Одесский национальний политехнический университет, г. Одесса

${ }^{2}$ Одесская государственная академия технического регулирования и качества, г. Одесса

\section{К РАСЧЕТУ КРУТИЛЬНЫХ КОЛЕБАНИЙ КОНСТРУКТИВНЫХ ЭЛЕМЕНТОВ ПОДЬЕМНО-ТРАНСПОРТНЫХ МАШИН МЕТОДОМ ГРАНИЧНЫХ ЭЛЕМЕНТОВ}

Приведены решения задачи Кочи крутильных колебаний тонкостенных стержней, которые являются составляющими элементами несущей системы подъемно-транспортных машин, с учетом всех членов уравнения В.З. Власова. Показано применение этих решений для задач динамики крутильных колебаний тонкостенных стержневых систем по алгоритму метода граничных элементов. Результаты решений приведены в численной и визуальных формах.

Ключевые слова: подъемно-транспортные машины, Matlab, метод граничных элементов, тонкостенный стержень, численные методы, крутильные колебания.

Тонкостенные стержневые конструктивные элементы подъемно-транспортных машин (ПТМ) имеют высокую прочность и жесткость с малой металлоемкостью. В этой связи они получили большое практическое применение в различных балочных и рамных конструкциях несущей системы ПТМ. Весьма важно иметь надежную и, достоверную теорию определения параметров крутильных колебаний тонкостенных элементов несущей системы ПТМ, с учетом того, что именно кручение является определяющим при расчете прочности и жесткости тонкостенных конструкций открытого профиля.
Уравнение и параметры крутильных колебаний прямолинейного тонкостенного стержня открытого профиля с двумя осями симметрии имеют вид [1]

$$
\begin{gathered}
E I_{\omega}=\frac{\partial^{4} \bar{\theta}(x, t)}{\partial x^{4}}-G I_{k p} \frac{\partial^{2} \bar{\theta}(x, t)}{\partial x^{2}}-\frac{\partial^{4} \bar{\theta}(x, t)}{\partial z^{2} \partial t^{2}}+ \\
+\rho\left(I_{z}+I_{y}\right) \frac{\partial^{2} \bar{\theta}(x, t)}{\partial t^{2}}=\bar{m}_{\lambda}(x, t), \\
\text { где } G I_{k p} \bar{\theta}(x, t) \quad-\text { динамический угол } \\
\text { поворота сечения стержня в масштабе }
\end{gathered}
$$

